\title{
Atrial arrhythmias after lung transplantation: Incidence and risk factors in 652 lung transplant recipients
}

\author{
Alex M. D'Angelo, BA, ${ }^{a}$ Ernest G. Chan, MD, MPH, ${ }^{a}$ J. W. Awori Hayanga, MD, MPH, ${ }^{a}$ \\ David D. Odell, MD, MMSc, ${ }^{\mathrm{a}}$ Joseph Pilewski, MD, ${ }^{\mathrm{b}}$ Maria Crespo, MD, ${ }^{\mathrm{b}}$ Matthew Morrell, MD, \\ Norihisa Shigemura, MD, ${ }^{a}$ James Luketich, MD, ${ }^{a}$ Christian Bermudez, MD, ${ }^{a}$ Andrew D. Althouse, PhD, \\ and Jonathan D'Cunha, $\mathrm{MD}, \mathrm{PhD}^{\mathrm{a}}$
}

\begin{abstract}
Objectives: Atrial arrhythmia (AA) after lung transplantation (LTx) is a potentially morbid event often associated with increased length of hospital stay. Predictors of postsurgical AA, however, are incompletely understood. We characterized the incidence and predisposing risk factors for AA in patients undergoing LTx.

Methods: A retrospective analysis of prospectively collected data was conducted to identify LTx recipients between January 2008 and October 2013. Patients were divided into 2 groups on the basis of postoperative AA development. Univariable and multivariable analyses were performed to define differences between groups and identify factors associated with AA. Survival differences were assessed by the use of competing risks methodology.
\end{abstract}

Results: A total of 198 of $652(30.4 \%)$ patients developed AA at a median onset of 5 days after transplant. Increasing age (hazard ratio [HR] 1.03 per additional year, $P<.001$ ) and previous coronary artery bypass grafting (HR 2.77, $P=.002$ ) were found to be independent risk factors. Counterintuitively, patients with a medical history of AA before LTx had a lower incidence of postoperative AA. Preoperative beta-blocker usage was not a significant predictor of postoperative AA. Postoperative AA was a significant predictor of long-term mortality (HR 1.63, $P=.007$ ) when we adjusted for other risk factors.

Conclusions: AA is a common occurrence after LTx, occurring with greatest frequency in the first postoperative week, and results in a significant reduction in long-term survival. Increasing age and before coronary artery bypass grafting were identified as independent risk factors for AA development. Better understanding of these risk factors may improve identification of patients at heightened risk after transplantation. (J Thorac Cardiovasc Surg 2016;152:901-9)

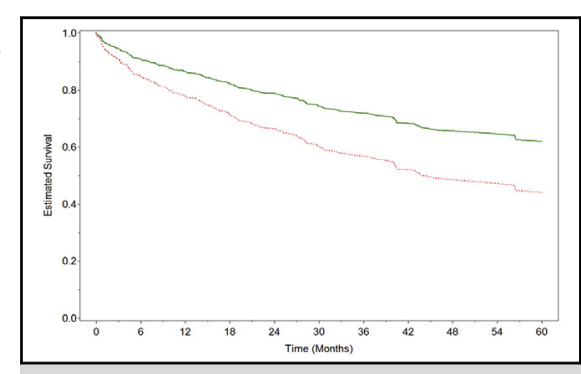

Atrial arrhythmia after lung transplantation negatively impacts survival.

\section{Central Message}

Atrial arrhythmia after lung transplant is a common and morbid event that is associated with a significant negative impact on long-term survival.

\section{Perspective}

We found atrial arrhythmia after lung transplant to be a common event that is associated with significantly reduced long-term survival. We anticipate these findings will help guide physicians in identifying patients more susceptible to atrial arrhythmia after lung transplant, with the ultimate goal of implementing interventions that have a lasting therapeutic impact.

See Editorial Commentary page 910.
Lung transplantation (LTx) is a potentially life-saving intervention for end-stage parenchymal lung and pulmonary vascular disease. Although there has been a reduction in the number of donor organs available, the annual procedure volume continues to increase. ${ }^{1}$ The development of atrial arrhythmia (AA) after LTx has been demonstrated to

\footnotetext{
From the Departments of ${ }^{\mathrm{a}}$ Cardiothoracic Surgery and ${ }^{\mathrm{b}}$ Pulmonary Medicine, and ${ }^{c}$ Heart and Vascular Institute, University of Pittsburgh Medical Center, Pittsburgh, $\mathrm{Pa}$.

Received for publication June 12, 2015; revisions received March 25, 2016; accepted for publication April 23, 2016; available ahead of print May 24, 2016.

Address for reprints: Jonathan D'Cunha, MD, PhD, Department of Cardiothoracic Surgery, University of Pittsburgh Medical Center, UPMC Presbyterian, Suite C-900, 200 Lothrop St, Pittsburgh, PA 15213 (E-mail: dcunhaj@upmc.edu). $0022-5223 / \$ 36.00$

Copyright (c) 2016 Published by Elsevier Inc. on behalf of The American Association for Thoracic Surgery

http://dx.doi.org/10.1016/j.jtcvs.2016.04.070
}

increase perioperative morbidity. ${ }^{2,3}$ The reported incidence of AA varies widely, ranging from $20 \%$ to $45 \%{ }^{2,4}$ Furthermore, previous authors have demonstrated the development of AA may increase perioperative mortality. ${ }^{4-6}$ A variety of mechanisms have been implicated in the postoperative development of AA, including inflammation, increased sympathetic tone, oxidative stress, structural predisposition, and operative technique (such as pulmonary venous line anastomosis). ${ }^{7-11}$

Scanning this QR code will take you to the article title page. 


$$
\begin{aligned}
& \text { Abbreviations and Acronyms } \\
& \text { AA }=\text { atrial arrhythmia } \\
& \text { BMI }=\text { body mass index } \\
& \text { CABG }=\text { coronary artery bypass grafting } \\
& \text { CAD }=\text { coronary artery disease } \\
& \text { DC }=\text { direct current cardioversion } \\
& \text { ICU }=\text { intensive care unit } \\
& \text { LOS }=\text { length of stay } \\
& \text { LTx }=\text { lung transplantation } \\
& \text { PAP }=\text { pulmonary arterial pressure } \\
& \text { POD }=\text { postoperative day } \\
& \text { UPMC }=\text { University of Pittsburgh Medical Center }
\end{aligned}
$$

In the current study, we retrospectively reviewed our institutional experience with patients who developed AA after LTx. In this analysis of LTx recipients, we aimed to clarify the incidence, risk factors, and postoperative survival of LTx recipients who develop AA.

\section{METHODS \\ Patients}

The study population includes patients who underwent single or double LTx at the University of Pittsburgh Medical Center (UPMC) between January 2008 and October 2013. This was an institutional review boardapproved study (PRO13040360). Patients undergoing combined heartlung transplants during this time period were excluded; patients undergoing retransplant also were excluded. Data on all 652 patients were obtained from the prospectively collected Cardiothoracic Transplant Database at UPMC. Our standard surgical approach has been described previously. ${ }^{12}$

\section{End Points}

The primary end point of the study was the in-hospital development of AA. Given the fact that other similar studies to ours have not discriminated between the types of AA, 3,5 atrial fibrillation and atrial flutter were not distinguished in our study. Although this decision may be interpreted as a limitation, we chose this approach to be able to compare our study with those performed previously. AA was defined by the Society of Thoracic Surgeons Adult Cardiac Surgery Database definition as those that were clinically documented or treated. Transient AA noted only on telemetry was not captured in the database and thus is not included in our analysis. Patients who experienced their initial episode of AA subsequent to their postoperative discharge from the hospital were categorized as non-AA patients in the analysis, because the event did not occur as an in-hospital event. The first day of AA development was used to calculate time from transplantation to arrhythmia onset. Recipients were all treated according to an institutional lung transplant patient care pathway, which did not include the routine use of prophylactic beta blockade or alternative AA prophylaxis. Data were not available regarding the duration of AA before conversion or hemodynamic status during AA events.

\section{Data Collection}

This retrospective analysis included a review of data entered into the UPMC Cardiothoracic Transplant Database, with database information obtained directly from in-patient records. All patients were monitored with continuous telemetry throughout the stay in the intensive care unit (ICU) and surgical transplant unit. A 12-lead electrocardiogram was obtained to confirm the rhythm in cases of documented AA.

\section{Statistical Analysis}

Descriptive characteristics are presented as n (\%) for categorical variables and median (interquartile range) for continuous variables. Univariable relationships between each of the baseline variables and development of postoperative AA were tested with either $\chi^{2}$ tests (categorical variables) or $t$ tests (continuous variables). Variables that were significantly associated with postoperative AA in univariable analyses were considered as potential predictors of postoperative AA in multivariable analysis: age at transplant, sex, body mass index (BMI), hypertension, hyperlipidemia, coronary artery disease $(\mathrm{CAD})$, previous coronary artery bypass grafting $(\mathrm{CABG})$, previous $\mathrm{AA}$, and transplant indication.

Risk factors for postoperative AA were assessed with the Fine-Gray model for analysis of competing risks. We felt this was a more appropriate model than the standard Cox proportional hazards model for this particular question, and support for this model has been provided recently. ${ }^{13}$ This model is appropriate for analysis of time-to-event data when the event of interest (in this case, AA within the hospitalization) can be impeded by a previous event of a different type; in this study, a patient's subsequent development of AA might be unobservable because the patient dies before development of AA is observed. Therefore, the patient is followed until the first of these 3 outcomes occurs: in-hospital development of AA, death inhospital before diagnosis of AA, or discharge from hospital free of AA. The patient is censored from further analysis when the first of these occurs.

To evaluate the effects of postoperative AA on survival in the long term, we used a Cox proportional-hazards model with postoperative AA included as a time-varying covariate. This model was used to compute estimated survival curves for patients with AA versus patients without AA to visually display the independent effects of AA on long-term survival. To capture the vast majority of AA cases and the relationship to outcome, survival analysis was started at posttransplant day 25 (examining only patients who survived to this time point), which also approximates our median length of hospital stay at the time the study was designed. We chose this endpoint to be congruent with other similar studies ${ }^{3}$ and enabled us to include more than $96 \%$ of AA cases that developed.

\section{RESULTS \\ Patient Characteristics}

A total of 652 patients underwent LTx during the study period. Median age at transplant was 61 years (interquartile range 50-67 years), and men represented $58 \%$ of the study population (379/652). Significant comorbid medical conditions in our population included hypertension $(37.4 \% ; 244 /$ $652)$, hyperlipidemia $(30.7 \% ; 200 / 652)$, diabetes $(20.6 \%$; $134 / 652)$, and CAD $(24.6 \% ; 161 / 652)$. Indications for LTx include fibrotic lung diseases (including scleroderma and idiopathic pulmonary fibrosis) $(47.1 \% ; 307 / 652)$, obstructive disease (including chronic obstructive pulmonary disease) $(35.4 \% ; 231 / 652)$, suppurative disease $(12.3 \%$; 80/652), pulmonary hypertension $(1.5 \% ; 10 / 652)$, and other (including retransplant from outside institutions) $(3.7 \% ; 24 / 652)$.

\section{Incidence and Timing}

AA developed in 198 of 652 patients (30.4\%). The largest single-day incidence of AA occurred on postoperative day 3 with a total of 28 new cases (Figure 1). A total of $67.7 \%(134 / 198)$ of arrhythmias occurred within the first postoperative week, whereas $97.5 \%$ (193/198) of cases developed within the first 30 days (range postoperative day [POD] 0-POD104). Among all patients who developed 


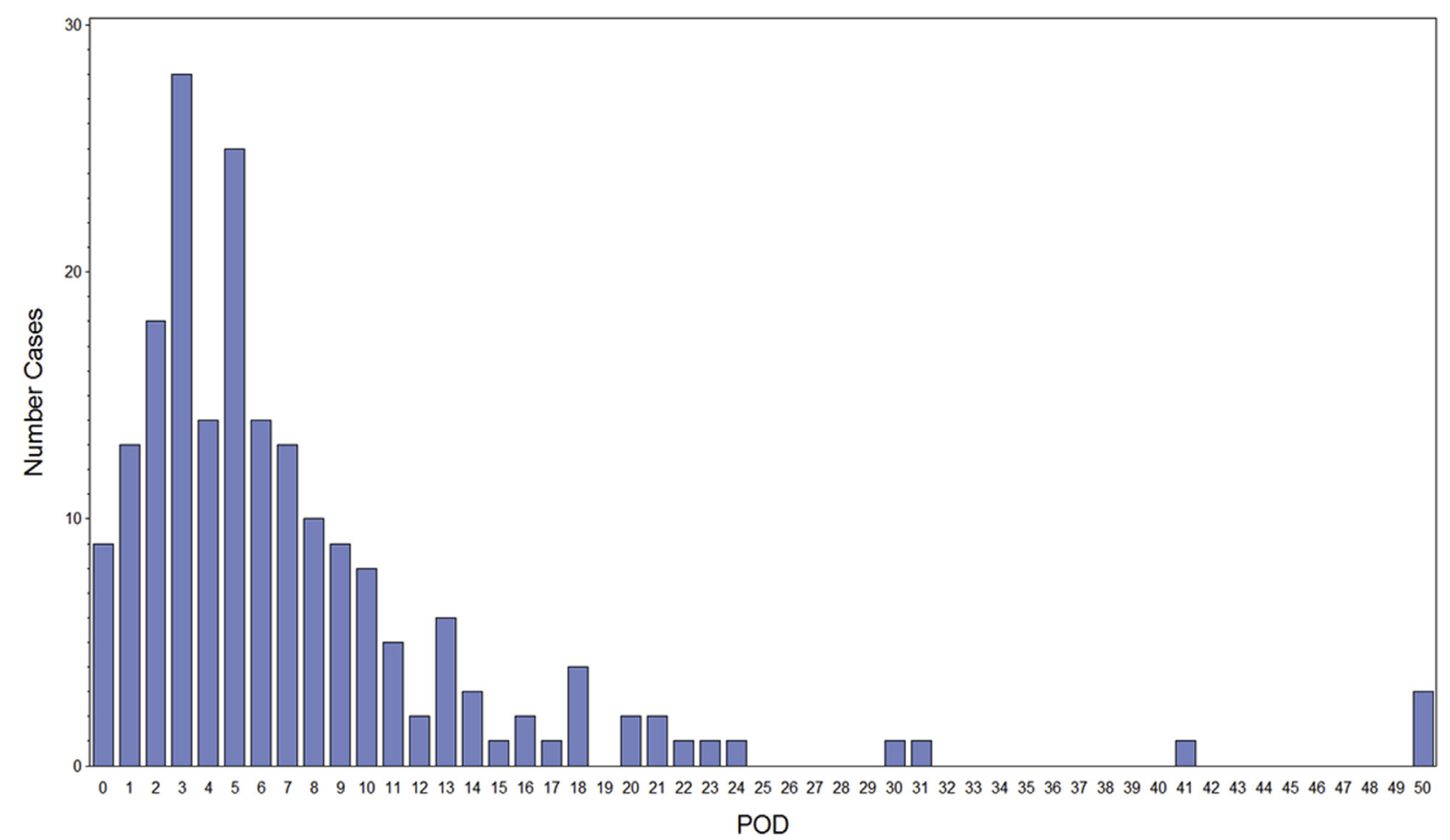

FIGURE 1. Incidence of AA per POD (within first 50 POD; $n=198$ ): AA events occurred most frequently within the first postoperative week, with the greatest number of events occurring on day 3. (Patients at risk). $P O D$, Postoperative day.

AA, the median time to manifestation of abnormal rhythm was 5 days.

\section{Risk Factors}

Table 1 illustrates the univariable relationships between each baseline characteristic and development of postoperative AA. Incidence of AA significantly increased with increasing age $(P<.001)$, and men were significantly more likely than women to develop AA $(34.6 \%$ vs $24.5 \%, P=.006)$. The risk of postoperative AA also increased significantly by BMI category $(P=.004)$, in patients with hypertension $(P<.001)$, in patients with hyperlipidemia $(P=.002)$, in patients with CAD $(P=.045)$, and in patients with previous CABG $(P=.001)$. The risk of postoperative AA also varied by transplant indication $(P<.001)$; only $8.8 \%$ of patients with suppurative disease experienced AA versus $31.2 \%$ with obstructive disease and $35.2 \%$ with fibrotic disease. Cardiac catheterization data is displayed in Table 2 for the 510 patients with available measurements. There were no significant relationships between catheterization measurements and postoperative AA.

Catheterization data were obtained on average greater than 1 year before LTx, generally around the time of listing. Other factors possibly associated with arrhythmia, such as thyroid disease and sleep apnea, were not included for analysis. Our database did not capture whether patients had a history of previous thoracic surgery. Ten patients underwent concomitant CABG at the time of LTx. Because of the low numbers of this group, we could not draw any conclusions regarding the incidence of AA and this rare combined procedure. Data on percutaneous coronary intervention is presented in Table 1. Timing of these interventions was not captured in the database.

Multivariable modeling showed age at transplant and previous $\mathrm{CABG}$ to have the strongest independent predictive value of postoperative AA. Each additional year of age was associated with a $3 \%$ increased risk of postoperative $\mathrm{AA}$, whereas patients with previous CABG had 2.28 times the risk of postoperative AA. There were very few pulmonary patients with hypertension in the database, but there was an indication that those patients also may be at high risk of developing AA. Other characteristics that showed modest associations in univariable analyses were attenuated when we adjusted for the remaining factors (Table 3).

\section{Treatment}

A total of 191 of 198 (96.4\%) patients received documented treatment for AA, with a variety of treatment regimens used (Table 4). Seven patients did not have documented treatment per detailed review of inpatient records. Rate control was achieved by the use of betablockers, calcium channel blockers, and digoxin. Rhythm control was achieved by the use amiodarone and sotalol. Direct current cardioversion (DC) was used in those 
TABLE 1. Incidence of postoperative atrial arrhythmia in selected baseline groups

\begin{tabular}{|c|c|c|c|c|}
\hline & No. patients & No postoperative AA & Postoperative AA & $P$ value \\
\hline Overall study group & 652 & $454(69.6 \%)$ & $198(30.4 \%)$ & \\
\hline Age, y & & & & $<.001$ \\
\hline$<40$ & 89 & $83(93.3 \%)$ & $6(6.7 \%)$ & \\
\hline $40-49$ & 66 & $47(71.2 \%)$ & $19(28.8 \%)$ & \\
\hline $50-59$ & 143 & $102(71.3 \%)$ & $41(28.7 \%)$ & \\
\hline $60-69$ & 278 & $181(65.1 \%)$ & $97(34.9 \%)$ & \\
\hline$>70$ & 76 & $41(53.9 \%)$ & $35(46.1 \%)$ & \\
\hline Sex & & & & .006 \\
\hline Female & 273 & $206(75.5 \%)$ & $67(24.5 \%)$ & \\
\hline Male & 379 & $248(65.4 \%)$ & $131(34.6 \%)$ & \\
\hline Race & & & & .394 \\
\hline White & 581 & $400(68.8 \%)$ & $181(31.2 \%)$ & \\
\hline Black & 42 & $33(78.6 \%)$ & $9(21.4 \%)$ & \\
\hline Other & 29 & $21(72.4 \%)$ & $8(27.6 \%)$ & \\
\hline Lung transplant & & & & .287 \\
\hline Single left lung & 67 & $47(70.1 \%)$ & $20(29.9 \%)$ & \\
\hline Single right lung & 30 & $17(56.7 \%)$ & $13(43.3 \%)$ & \\
\hline Double lung & 555 & $390(70.3 \%)$ & $165(29.7 \%)$ & \\
\hline BMI & & & & .004 \\
\hline$<25$ & 272 & $207(76.1 \%)$ & $65(23.9 \%)$ & \\
\hline $25-30$ & 177 & $112(63.3 \%)$ & $65(36.7 \%)$ & \\
\hline $30-35$ & 113 & $75(66.4 \%)$ & $38(33.6 \%)$ & \\
\hline$>35$ & 24 & $12(50.0 \%)$ & $12(50.0 \%)$ & \\
\hline HTN & & & & $<.001$ \\
\hline No & 408 & $304(74.5 \%)$ & $104(25.5 \%)$ & \\
\hline Yes & 244 & $150(61.5 \%)$ & $94(38.5 \%)$ & \\
\hline HLD & & & & .002 \\
\hline No & 452 & $331(73.2 \%)$ & $121(26.8 \%)$ & \\
\hline Yes & 200 & $123(61.5 \%)$ & $77(38.5 \%)$ & \\
\hline DM & & & & .783 \\
\hline No & 518 & $362(69.9 \%)$ & $156(30.1 \%)$ & \\
\hline Yes & 134 & $92(68.7 \%)$ & $42(31.3 \%)$ & \\
\hline CAD & & & & .045 \\
\hline No & 491 & $352(71.7 \%)$ & $139(28.3 \%)$ & \\
\hline Yes & 161 & $102(63.4 \%)$ & $59(36.6 \%)$ & \\
\hline Previous CABG & & & & .001 \\
\hline No & 632 & $447(70.7 \%)$ & $185(29.3 \%)$ & \\
\hline Yes & 20 & $7(35.0 \%)$ & $13(65.0 \%)$ & \\
\hline Previous PCI & & & & .332 \\
\hline No & 569 & $400(70.3 \%)$ & $169(29.7 \%)$ & \\
\hline Yes & 83 & $54(65.1 \%)$ & $29(34.9 \%)$ & \\
\hline Previous atrial arrhythmia & & & & .001 \\
\hline No & 576 & $389(67.5 \%)$ & $187(32.5 \%)$ & \\
\hline Yes & 76 & $65(85.5 \%)$ & $11(14.5 \%)$ & \\
\hline Preoperative beta blockers & & & & .155 \\
\hline No & 524 & $372(71.0 \%)$ & $152(29.0 \%)$ & \\
\hline Yes & 128 & $82(64.1 \%)$ & $46(35.9 \%)$ & \\
\hline Transplant indication & & & & $<.001$ \\
\hline Obstructive disease & 231 & $159(68.8 \%)$ & $72(31.2 \%)$ & \\
\hline Suppurative disease & 80 & $73(91.3 \%)$ & $7(8.8 \%)$ & \\
\hline Fibrotic disease & 307 & $199(64.8 \%)$ & $108(35.2 \%)$ & \\
\hline Pulmonary hypertension & 10 & $5(50.0 \%)$ & $5(50.0 \%)$ & \\
\hline Other & 24 & $18(75.0 \%)$ & $6(25.0 \%)$ & \\
\hline
\end{tabular}

$A A$, Atrial arrhythmia; $B M I$, body mass index; $H T N$, hypertension; $H L D$, heart-lung disease; $D M$, diabetes mellitus; $C A D$, coronary artery disease; $C A B G$, coronary artery bypass grafting; $P C I$, percutaneous coronary intervention. 
TABLE 2. Cardiac catheterization and supplemental data

\begin{tabular}{|c|c|c|c|c|}
\hline & No. patients & No postoperative AA & Postoperative AA & $P$ value \\
\hline PA systolic pressure & 510 & $41(35,52)$ & $41(35,53)$ & .811 \\
\hline PA diastolic pressure & 509 & $14(10,21)$ & $15(11,21)$ & .394 \\
\hline RV systolic pressure & 510 & $40(34.5,50.5)$ & $41(35,52)$ & .418 \\
\hline RV diastolic pressure & 505 & $3(0,6)$ & $3(0,6)$ & .744 \\
\hline Mean RV pressure & 443 & $8(5,11)$ & $8(5.5,11)$ & .902 \\
\hline Right atrial pressure & 510 & $6(3.5,9)$ & $6(4,9)$ & .539 \\
\hline Cardiac output & 463 & $5.2(4.6,6.1)$ & $5.4(4.6,6.4)$ & .134 \\
\hline Cardiac index & 457 & $2.9(2.5,3.3)$ & $2.9(2.5,3.4)$ & .862 \\
\hline Fick CO & 433 & $5.8(5,6.5)$ & $6(5.1,7)$ & .105 \\
\hline Fick CI & 431 & $3.1(2.7,3.6)$ & $3(2.7,3.5)$ & .749 \\
\hline PCWP & 504 & $11(8,14)$ & $12(9,15)$ & .107 \\
\hline \multicolumn{5}{|l|}{ Supplemental patient data } \\
\hline Wait list time & 652 & $35(11,106)$ & $39.5(13,112)$ & .928 \\
\hline LAS score & 652 & $40.3(34.2,55.3)$ & $41.8(34.9,59.8)$ & .350 \\
\hline $\mathrm{CPB}$ time (if $\mathrm{CPB}$ used) & 220 & $238(159,288)$ & $258(164,303)$ & .211 \\
\hline Ischemic time, $\min$ & 637 & $334(296,385)$ & $332(290,385)$ & .683 \\
\hline Initial time on ventilator, $\mathrm{h}$ & 644 & $30(17,73)$ & $49(21,171)$ & $<.001$ \\
\hline ICU time, $\mathrm{d}$ & 644 & $5(3,13)$ & $13(5,25)$ & $<.001$ \\
\hline Total hospital stay, d & 608 & $28(18,46)$ & $39(25,65)$ & $<.001$ \\
\hline
\end{tabular}

$A A$, Atrial arrhythmia; $P A$, pulmonary artery; $R V$, right ventricular; $C O$, cardiac output; $C I$, cardiac index; $P C W P$, pulmonary capillary wedge pressure; $L A S$, lung allocation score; $C P B$, cardiopulmonary bypass; $I C U$, intensive care unit.

patients who were hemodynamically unstable. The largest proportion of patients $(42.4 \% ; 81 / 191)$ was managed with rate control alone, with metoprolol used in nearly all cases. This treatment strategy was followed in frequency by isolated DC in $17.3 \%(33 / 191)$ of patients.

\section{Preoperative Use of Beta-Blockers/History of AA}

Given the uncertain role of prophylactic beta-blockers in noncardiac surgery, we examined the proportion of patients on beta-blockers at the time of surgery. A total of $19.6 \%$ $(128 / 652)$ of our patients were documented to be taking a beta-blocker at the time of transplant. Counterintuitively, a slightly greater proportion of patients taking beta blockers

TABLE 3. Multivariable risk factor analysis for development of posttransplant AA

\begin{tabular}{lccr}
\hline \multicolumn{1}{c}{ Risk factor } & Adjusted HR & $\mathbf{9 5} \%$ CI & $\boldsymbol{P}$ value \\
\hline Age at transplant (per year) & 1.03 & $(1.01,1.05)$ & $<.001$ \\
Male sex & 1.30 & $(0.91,1.83)$ & .138 \\
BMI (per 1 kg/m ${ }^{2}$ ) & 1.01 & $(0.97,1.04)$ & .629 \\
Hypertension & 1.23 & $(0.90,1.68)$ & .191 \\
Hyperlipidemia & 1.20 & $(0.85,1.68)$ & .294 \\
CAD & 0.76 & $(0.53,1.08)$ & .124 \\
Previous CABG & 2.77 & $(1.44,5.30)$ & .002 \\
Previous arrhythmia & 0.28 & $(0.10,0.55)$ & $<.001$ \\
Disease category (ref = suppurative) & & & \\
Obstructive & 1.68 & $(0.65,4.31)$ & .277 \\
Fibrotic disease & 1.75 & $(0.60,4.43)$ & .236 \\
Pulmonary hypertension & 2.89 & $(0.78,10.5)$ & .109 \\
Other & 1.67 & $(0.47,5.89)$ & .427 \\
\hline
\end{tabular}

$H R$, Hazard ratio; $C I$, confidence interval; $B M I$, body mass index; $C A D$, coronary artery disease; $C A B G$, coronary artery bypass grafting. at the time of LTx developed postoperative AA $(35.9 \%, 46 /$ 128 vs $29.0 \%, 152 / 524)$, although this difference was not statistically significant.

Preoperative AA was found to be documented in the previous medical history of 76 of the 652 patients $(11.7 \%)$. It is unknown whether the historical arrhythmias were transient or required treatment. Patients with a history of arrhythmia were surprisingly less likely to develop postoperative AA $(14.5 \%$ vs $32.5 \%, P<.001)$.

\section{Hospital Discharge}

All patients were confirmed to have returned to normal sinus rhythm at time of discharge via physical examination. On hospital discharge, $91.2 \%(156 / 171)$ of patients were prescribed medications for the long-term management of AA; $8.8 \%(15 / 171)$ of patients were not prescribed medications for control of AA. Of those treated after discharge, $84.0 \%(131 / 156)$ received rate control alone, whereas $14.1 \%(22 / 156)$ received only rhythm control. The

TABLE 4. Treatment strategies for AA

\begin{tabular}{lc}
\hline Treatment strategy & n (\%) \\
\hline Rate & $81(40.9)$ \\
Rhythm & $11(5.5)$ \\
Rate and rhythm & $10(5.0)$ \\
Rate and DC & $28(14.1)$ \\
Rhythm and DC & $18(9.1)$ \\
Rate/rhythm and DC & $10(5.0)$ \\
DC alone & $33(16.7)$ \\
Unclear & $7(3.5)$ \\
\hline
\end{tabular}

$D C$, Direct current cardioversion. 


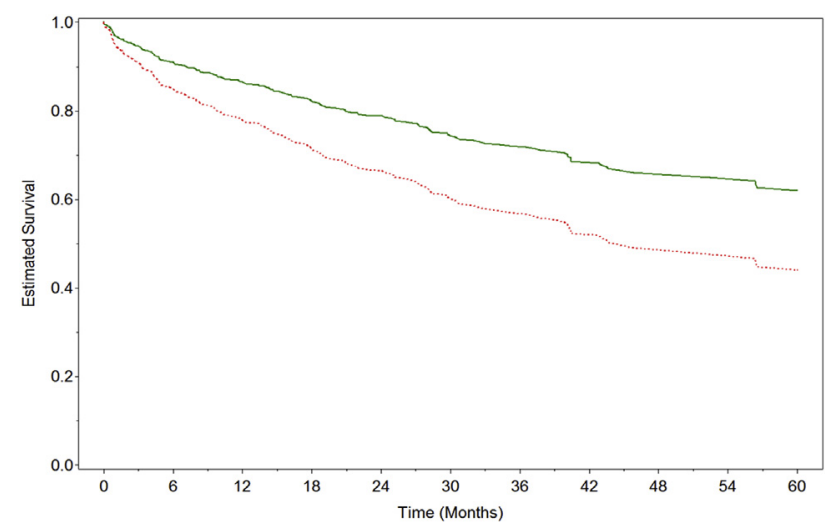

FIGURE 2. Competing risk survival analysis in patients who develop AA after LTx: estimated survival among patients who developed AA postoperatively versus those who $\operatorname{did} \operatorname{not}(P=.02)$.

remaining $1.9 \%$ (3/156) received both rate and rhythm control. Rate control was achieved with metoprolol in nearly all cases, whereas sotalol was the only antiarrhythmic used.

\section{Impact on Length of Stay (LOS) and Survival}

Patients who developed AA experienced significantly longer ICU (median 13 days vs median 5 days, $P<.001$ ) and overall hospital stays (median 39 days vs median 28 days, $P<.001$ ) compared with patients who maintained sinus rhythm throughout their postoperative period. Longterm survival was reduced significantly in patients who developed AA versus those who did not develop AA (Figure 2). Eighteen patients experienced mortality before POD25 and were omitted from analysis. Ten of these 18 patients developed AA before death.

Further multivariable analysis was conducted to assess whether postoperative AA was among the independent risk factors for mortality. Postoperative arrhythmia was significantly associated with increased risk of mortality (Table 5, hazard ratio $1.63, P=.007$ ) when we accounted for other risk factors. Age at transplant, hypertension, and previous CAD also were at least moderately associated with an increased risk of mortality, as was the transplant indication (specifically, obstructive disease and fibrotic disease had lower risk than suppurative disease).

\section{DISCUSSION}

AA after LTx is a common and morbid event. This is the largest study to date that addresses its incidence, risk factors, and impact on survival.

\section{Incidence and Timing}

The reported incidence of AA ranges from $20 \%$, reported by Mason et $\mathrm{al}^{3}$ in a series of 333 patients, to a peak of $45 \%$, published by Isiadinso et $\mathrm{al}^{4}$ with a cohort of 137 patients. Typical peak incidence onset was seen by Mason et $\mathrm{al}^{3}$ to be 2 days after having received surgery, with an average
TABLE 5. Multivariable risk factor analysis for mortality

\begin{tabular}{lccc}
\hline \multicolumn{1}{c}{ Risk factor } & Adjusted HR & $\mathbf{9 5} \%$ CI & $\boldsymbol{P}$ value \\
\hline Age at transplant (per year) & 1.02 & $(1.00,1.04)$ & .019 \\
Male sex & 0.89 & $(0.62,1.28)$ & .535 \\
BMI (per $\left.1 \mathrm{~kg} / \mathrm{m}^{2}\right)$ & 0.98 & $(0.90,1.02)$ & .344 \\
Hypertension & 1.36 & $(0.94,1.97)$ & .097 \\
Hyperlipidemia & 0.70 & $(0.46,1.06)$ & .092 \\
CAD & 1.44 & $(0.94,2.20)$ & .086 \\
Previous CABG & 1.02 & $(0.40,2.47)$ & .958 \\
Previous arrhythmia & 1.34 & $(0.82,2.20)$ & .238 \\
Disease category (ref = suppurative) & & & \\
$\quad$ Obstructive & 0.36 & $(0.17,0.74)$ & .005 \\
Fibrotic disease & 0.42 & $(0.20,0.85)$ & .016 \\
Pulmonary hypertension & 1.16 & $(0.37,3.57)$ & .797 \\
$\quad$ Other & 0.74 & $(0.30,1.80)$ & .506 \\
Postoperative arrhythmia & 1.63 & $(1.10,2.33)$ & .007 \\
\hline
\end{tabular}

$\overline{H R}$, Hazard ratio; $C I$, confidence interval; $B M I$, body mass index; $C A D$, coronary artery disease; $C A B G$, coronary artery bypass grafting.

time of onset of 7 days reported by both Orrego et al ${ }^{6}$ and Henri et al. ${ }^{14}$ These findings are in line with the results of our study. However, the larger size of our patient cohort increases the statistical validity of the results. AA was quite common in our patient population, with an incidence of $30.4 \%$. The median time-to-AA onset in those developing AA was postoperative day 5, with the peak incidence being reached on postoperative day 3 . A second peak in incidence occurred on postoperative day 5 . We are uncertain of the etiology of this bimodal peak seen in Figure 1. Understanding the timing of AA events may be key in creating targeted clinical pathways, with the goal of initially decreasing and ultimately eliminating the morbidity associated with AA in patients undergoing LTx.

\section{Risk Factors}

Previous investigators have reported older age, increased weight, cardiac valvulopathy, fibrotic lung disease, and male sex as significant risk factors for the development of AA after surgery. ${ }^{3,5,6,14}$ Pulmonary arterial pressure (PAP) and its effects on AA have been a point of contention in the literature. Mason et $\mathrm{al}^{3}$ reported that elevated PAP increases risk of $\mathrm{AA}$, whereas Malik et $\mathrm{al}^{15}$ reported that high pulmonary pressures are protective from AA. There is also conflicting evidence on the impact of single versus double LTx. Lee et $\mathrm{al}^{16}$ found single lung transplant to be a risk factor for the development of AA, whereas Henri et $\mathrm{a}^{14}$ reported double LTx as being significantly associated with AA. Although conducted at a cancer center where LTx is not performed, Vaporciyan et al ${ }^{17}$ examined risk factors for AA in thoracic surgery and found that a history of previous thoracic surgery was present in a significantly larger proportion of those developing acute postoperative AA. However, this was not found to be significant in multivariable analysis. 
In univariable analysis of our cohort, we have identified several factors associated with the development of AA: older age, male sex, increased BMI, history of hypertension, history of hyperlipidemia, history of CAD, and previous CABG. Many of these factors are common to those identified by previous investigators. ${ }^{3,5,6,14}$ Interestingly, in contrast to Mason et al's study, our data did not identify a significant correlation between PAP and AA. We also found no significant difference in the proportion of patients requiring cardiopulmonary bypass in patients developing AA versus the non-AA group.

With multivariable modeling, however, only increased age and previous $\mathrm{CABG}$ were found to be independent risk factors for AA. Surprisingly, preoperative history of AA was found to be an independent protective factor for postoperative AA. To our knowledge, this is the first report of previous $\mathrm{CABG}$ as an independent risk factor for AA. Given this finding, further exploration of the relationship of previous cardiac surgery and postoperative AA in patients undergoing pulmonary transplant surgery may be warranted.

Recognition of those patients at heightened risk may allow for improved monitoring and early initiation of treatment, which hopefully will result in improved outcomes. Our results certainly raise some cautionary flags when considering future listing of patients with a history of previous CABG.

Underlying pulmonary disease diagnosis also was found by univariable analysis to have implications for the development of AA in LTx patients postoperatively. Although significantly more patients transplanted for fibrotic disease developed AA, the incidence of AA was significantly lower in patients transplanted for suppurative disease. There were no significant differences, however, in the development of AA in our multivariable model based on LTx indication.

Our average ischemic times per patient were not significantly different between those developing AA and those maintaining sinus rhythm. We recognize, however, that the times are longer than one might anticipate. We theorize this may be secondary to such factors as our willingness to travel further afield for suitable donors and recipient complexity, as roughly $30 \%-40 \%$ of our recipients are declined by other centers for surgical issues. To more broadly investigate this, we found that these findings are in keeping with recently published analyses of United Network for Organ Sharing and The International Society for Heart and Lung Transplantation datasets, which show that United Network for Organ Sharing high-volume centers have longer ischemic times (on aggregate) for the lung transplants they perform. ${ }^{18}$

\section{Impact on LOS and Survival}

Previous studies have shown an increased length of hospital stay in patients developing AA after transplant. ${ }^{3,5}$
Mason et $\mathrm{al}^{3}$ showed a 3-day increased LOS, whereas Nielson et $\mathrm{al}^{5}$ found an increase of nearly 15 days. Both Nielson et $\mathrm{al}^{5}$ and Orrego et $\mathrm{al}^{6}$ report significantly reduced survival in patients who develop AA. Mason et al, ${ }^{3}$ however, did not find a significant increase in mortality up to 6 years after surgery. These investigators attributed these findings to their aggressive treatment strategy.

We found that patients who developed AA had a LOS in the ICU that was on average 8 days longer than those who remained in sinus rhythm throughout their hospital stay. The entire hospital stay was on average 11 days longer for those with AA. We acknowledge that our overall hospital LOS is surprisingly long. Explanations for this include the complexity of recipients and multiple comorbidities. More importantly, before late 2012 there was no standardized approach to clinical care in the postoperative setting. The senior author (J.D.) arrived at the institution at that time and put forth a detailed clinical pathway that is now used actively and median LOS has been reduced to approximately 22 days. This rate has been stable for 2 years. Although this is still longer than one might expect, $40 \%$ of our patients were turned down at other institutions as the result of comorbid medical conditions, which highlights the importance of the utilization of clinical pathways in postoperative management.

To conclude that increased LOS of our patients developing AA is a result of arrhythmia and not simply an association with patients who have greater medical comorbidities, we conducted multivariable regression analysis of predictors of increased LOS. We found that AA and cardiopulmonary bypass were significant independent predictors. Thus, we conclude that the development of postoperative AA is a factor relating to increased hospital stay.

Survival analysis (Figure 2 ) beginning at +25 days posttransplant revealed significantly greater mortality up to 6 years after transplant in patients developing postoperative AA $(P=.02)$. It is important to note that at our institution, we implement similar treatment regimens to Mason et al. ${ }^{3}$ Furthermore, when our entire cohort was analyzed (including those who did not survive to POD25), AA remained associated with significantly reduced survival. We subsequently conducted a multivariable regression analysis of predictors of mortality to clarify the direct effect of AA on survival. We found AA to be an independent predictor of mortality when accounting for other factors. Pretransplant comorbidities, including age, sex, race, BMI, history of CAD, hyperlipidemia, diabetes, hypertension, and PAP, were not found to be significantly related to mortality.

On the basis of our findings, we conclude that the development of postoperative AA has significant direct impact on survival. Furthermore, lowering both ICU and overall hospital stay may have financial implications for institutions that offer LTx as treatment. Because of this finding, prophylactic treatment strategies against AA may improve survival 
well beyond the initial postoperative period and should be investigated further.

\section{Treatment of AA and Preoperative Use of Beta- Blockers}

Treatment of AA in our population of lung transplant patients proved to be patient specific, often requiring multiple treatment modalities to achieve rhythm control. The single largest treatment category was solely rate control $(43 \%$ of patients with AA), with metoprolol as the drug of choice. This was followed by $17 \%$ of patients receiving DC alone. A total of $26 \%$ of patients received some form of rhythm control, most often in combination with another form of treatment (DC, rate control). Although the treatment of AA in our population was somewhat tailored to the patient's clinical status at the time of the rhythm disturbance, rhythm control was almost always with use of either sotalol or amiodarone. A total of $68 \%$ of patients received DC, also often in combination with another form of treatment. The use of DC at our institution was much greater than what is reported by both Orrego et $\mathrm{al}^{3}(13 \%)$ and Mason et $\mathrm{al}^{6}$ $(30 \%)$. DC was used so heavily in combination with other treatment modalities in our patients because arrhythmia often was refractory to medical management and required subsequent electrical conversion to sinus rhythm. DC was used alone in $17.3 \%$ of patients. Because of hemodynamic instability in these patients at the time AA was occurring, it was deemed necessary to forego medical management and attempt cardioversion. Rate of cardioversion fell from $46.4 \%$, during the study period, to $33.3 \%$ between August 2014 and August 2015, corresponding to changes instituted by the senior author (J.D.).

Beta-blockers have long been recognized as beneficial in the prophylaxis of postoperative AA. ${ }^{19-22}$ The majority of research has focused on AA after heart surgery and supports the use of beta-blockers to reduce the incidence of postoperative AA, in addition to reducing overall cardiovascular events ${ }^{21,23-25}$; however, the data are somewhat uncertain for noncardiac surgery. Authors of the POISE (patients undergoing non-cardiac surgery) study, a multicenter randomized, controlled trial of the administration of high-dose metoprolol beginning on the day of surgery, ${ }^{26}$ found that although cardiovascular events were reduced in the beta-blocker group, overall mortality and stroke rate were increased. These findings were likely the result of beta-blocker-induced hypotension and bradycardia. ${ }^{19,26}$ In patients undergoing noncardiac thoracic surgery, the Society of Thoracic Surgeons currently recommends continuing preoperative beta-blockers and states that both diltiazem and beta-blockers are reasonable choices for AA prophylaxis but cautions that beta-blockers may be associated with greater side effects. ${ }^{27}$ On the basis of data obtained from our transplant database, we found no statistical difference in the development of AA based on beta-blocker usage. Given that preoperative AA was an independent protective factor in the development of postoperative AA in multivariable analysis, it was expected that a significantly greater proportion of patients who maintained sinus rhythm also would have been on preoperative betablockers. Additionally, there may be some protective effect from the atrial suture lines related to the pulmonary vein anastomoses, as described by others. ${ }^{16}$ Thus, in our population of LTx recipients, these limited data suggest that betablockers are not effective in preventing postoperative AA. This is a potentially important correlative finding.

\section{Study Limitations}

This study represents the clinical experience at a single institution examined in a retrospective manner and the findings may not be uniformly transferrable to other centers. As with all retrospective studies, there is possible selection bias, difficulty detecting rare risk factors, and inability to infer causality. Treatment of AA did not follow unified treatment algorithms for all patients and was subject to physician and patient-specific clinical intervention. Cumulative comorbidity aggregate was not currently available for analysis through our database and the study period.

\section{CONCLUSIONS}

We have characterized postoperative AA after LTx in the largest patient series to date. AA is a common and morbid event, with significantly increased mortality years after surgery. Increasing age and previous $\mathrm{CABG}$ were found to be significant risk factors in multivariable analysis. AA was shown to be an independent predictor of mortality over the long term. Beta-blocker usage at the time of surgery was not protective in the development of AA, which, to our knowledge, is the first time this is reported in the LTx population. With progressively older individuals receiving donor organs, it will become increasingly important to prophylactically manage postoperative AA. It is our intention to use findings to guide physicians in identifying patients more susceptible to AA post-LTx with the ultimate goal of implementing interventions that have a lasting therapeutic impact. We have already found these findings useful in the pretransplant counseling of patients being listed for LTx regarding expectations in the postoperative setting. It is clear that additional studies are needed to further define the optimal treatment strategy for AA in patients undergoing LTx, and we submit that our study provides much-needed information for this important area of future investigation.

\section{Conflict of Interest Statement}

Dr Luketich reports equity ownership in Intuitive Surgical. All other authors have nothing to disclose with regard to commercial support. 


\section{References}

1. Whitson BA, Hayes D Jr. Indications and outcomes in adult lung transplantation. J Thorac Dis. 2014;6:1018-23.

2. See VY, Roberts-Thomson KC, Stevenson WG, Camp PC, Koplan BA. Atrial arrhythmias after lung transplantation: epidemiology, mechanisms at electrophysiology study, and outcomes. Circ Arrhythm Electrophysiol. 2009;2:504-10.

3. Mason DP, Marsh DH, Alster JM, Murthy SC, McNeill AM, Budev MM, et al. Atrial fibrillation after lung transplantation: timing, risk factors, and treatment. Ann Thorac Surg. 2007;84:1878-84.

4. Isiadinso I, Meshkov AB, Gaughan J, Sandhu P, Lim S, Cordova F, et al. Atrial arrhythmias after lung and heart-lung transplant: effects on short-term mortality and the influence of amiodarone. J Heart Lung Transplant. 2011;30:37-44.

5. Nielsen TD, Bahnson T, Davis RD, Palmer SM. Atrial fibrillation after pulmonary transplant. Chest. 2004;126:496-500.

6. Orrego CM, Cordero-Reyes AM, Estep JD, Seethamraju H, Scheinin S, Loebe M, et al. Atrial arrhythmias after lung transplant: underlying mechanisms, risk factors, and prognosis. J Heart Lung Transplant. 2014;33:734-40.

7. Maesen B, Nijs J, Maessen J, Allessie M, Schotten U. Post-operative atrial fibrillation: a maze of mechanisms. Europace. 2012;14:159-74.

8. Shingu Y, Kubota S, Wakasa S, Ooka T, Tachibana T, Matsui Y. Postoperative atrial fibrillation: mechanism, prevention, and future perspective. Surg Today. 2012;42:819-24.

9. Echahidi N, Pibarot P, O'Hara G, Mathieu P. Mechanisms, prevention, and treatment of atrial fibrillation after cardiac surgery. J Am Coll Cardiol. 2008;51: 793-801.

10. Gandhi SK, Bromberg BI, Schuessler RB, Boineau JP, Cox JL, Huddleston CB. Left-sided atrial flutter: characterization of a novel complication of pediatric lung transplantation in an acute canine model. J Thorac Cardiovasc Surg. 1996;112: 992-1001.

11. Bazaz R, Salizzoni S, Bonde P, Espinoza A, Toyoda Y. A novel strategy for prevention of post-operative atrial arrhythmias in patients undergoing lung transplantation. J Heart Lung Transplant. 2010;29:713-5.

12. Hayanga JW, D'Cunha J. The surgical technique of bilateral sequential lung transplantation. J Thorac Dis. 2014;6:1063-9.

13. Austin PC, Lee DS, Fine JP. Introduction to the analysis of survival data in the presence of competing risks. Circulation. 2016;133:601-9.

14. Henri C, Giraldeau G, Dorais M, Cloutier AS, Girard F, Noiseux N, et al. Atrial fibrillation after pulmonary transplantation: incidence, impact on mortality, treatment effectiveness, and risk factors. Circ Arrhythm Electrophysiol. 2012; 5:61-7.

15. Malik A, Hsu JC, Hoopes C, Itinarelli G, Marcus GM. Elevated pulmonary artery systolic pressures are associated with a lower risk of atrial fibrillation following lung transplantation. J Electrocardiol. 2013;46:38-42.

16. Lee G, Wu H, Kalman JM, Esmore D, Williams T, Snell G, et al. Atrial fibrillation following lung transplantation: double but not single lung transplant is associated with long-term freedom from paroxysmal atrial fibrillation. Eur Heart J. 2010 31:2774-82.

17. Vaporciyan AA, Correa AM, Rice DC, Roth JA, Smythe WR, Swisher SG, et al. Risk factors associated with atrial fibrillation after noncardiac thoracic surgery: analysis of 2588 patients. J Thorac Cardiovasc Surg. 2004;127: 779-86.

18. Hayanga AJ, Vlahu T, D’Cunha J, Hayanga HK, Girgis R, Khaghani A. Effect of center volume on survival after lung re-transplantation. J Heart Lung Transplant. 2015;34:S254.

19. Omae T, Kanmura Y. Management of postoperative atrial fibrillation. J Anesth 2012;26:429-37.

20. Arsenault KA, Yusuf AM, Crystal E, Healey JS, Morillo CA, Nair GM, et al. Interventions for preventing post-operative atrial fibrillation in patients undergoing heart surgery. Cochrane Database Syst Rev. 2013;1:Cd003611.

21. Burgess DC, Kilborn MJ, Keech AC. Interventions for prevention of postoperative atrial fibrillation and its complications after cardiac surgery: a metaanalysis. Eur Heart J. 2006;27:2846-57.

22. Sedrakyan A, Treasure T, Browne J, Krumholz H, Sharpin C, van der Meulen J. Pharmacologic prophylaxis for postoperative atrial tachyarrhythmia in general thoracic surgery: evidence from randomized clinical trials. J Thorac Cardiovasc Surg. 2005;129:997-1005.

23. Crystal E, Garfinkle MS, Connolly SS, Ginger TT, Sleik K, Yusuf SS. Interventions for preventing post-operative atrial fibrillation in patients undergoing heart surgery. Cochrane Database Syst Rev. 2004;Cd003611.

24. Sezai A, Nakai T, Hata M, Yoshitake I, Shiono M, Kunimoto S, et al. Feasibility of landiolol and bisoprolol for prevention of atrial fibrillation after coronary artery bypass grafting: a pilot study. J Thorac Cardiovasc Surg. 2012;144: 1241-8.

25. Sezai A, Minami K, Nakai T, Hata M, Yoshitake I, Wakui S, et al. Landiolol hydrochloride for prevention of atrial fibrillation after coronary artery bypass grafting: new evidence from the PASCAL trial. J Thorac Cardiovasc Surg. 2011;141: 1478-87.

26. Devereaux PJ, Yang H, Yusuf S, Guyatt G, Leslie K, Villar JC, et al. Effects of extended-release metoprolol succinate in patients undergoing non-cardiac surgery (POISE trial): a randomised controlled trial. Lancet. 2008;371: $1839-47$.

27. Fernando HC, Jaklitsch MT, Walsh GL, Tisdale JE, Bridges CD, Mitchell JD et al. The Society of Thoracic Surgeons practice guideline on the prophylaxis and management of atrial fibrillation associated with general thoracic surgery: executive summary. Ann Thorac Surg. 2011;92:1144-52.

Key Words: atrial arrhythmias, atrial fibrillation, atrial flutter, lung transplantation 